\title{
Research on the Incentive Ways of Logistics Staff in Universities from the Perspective of Socialization
}

\author{
Chen Chaochao ${ }^{1, a}$ \\ ${ }^{1}$ Logistics Department, China West Normal University, Nanchong City, Sichuan Province, 637000, \\ China \\ aemail:
}

Keywords: socialization; universities; logistics; staff motivation; ways

\begin{abstract}
With the gradual deepening of socialization reform of logistics in universities, it is extremely necessary to implement scientific and reasonable staff incentive measures. However, the problems that the incentive concepts of the current college logistics enterprise managers lag behind, and incentive measures lack necessary supports are still very serious. Therefore, it is necessary to take the incentive measures suitable for the staff to effectively stimulate the enthusiasm of the logistics staff. In this paper, based on the author's learning and practical experience, we first discussed the related issues of the motivation of college logistics staff from the perspective of socialization, and then analyzed the existing problems of the motivation of college logistics staff. Finally, the ways of college logistics staff motivation were put forward.
\end{abstract}

\section{Introduction}

The college logistics refers to the provision of material conditions and services for college teaching, research and life of teachers and students, which is the foundation and guarantee of the management system of universities in China ${ }^{[1]}$. College logistics staff is a group which provides solid logistical support for teachers and students. The enthusiasm of the staff plays a decisive role in the scientific, healthy and sustainable development of logistics enterprises. The personnel management is most important part in the logistics management. The important way to solve the above problems is how to maximize the mobilization of the enthusiasm, initiative and creativity of staff at different positions to make the potential of individuals be transferred into the whole efficiency and profits of logistics group, and reveal the scientific and reasonable incentive mechanism ${ }^{[2]}$.

\section{Interpretation of the Incentive Problems of Logistics Staff in Universities from the Perspective of Socialization}

Motivation is to motivate the behavioral motive of the staff, that is, mobilize the enthusiasm and creativity of the staff via various effective methods to make the staff thrive for the completion of the organizational tasks and objectives. The incentive mechanism is to reflect the way of the interaction between the incentive subject and incentive object via a rational system. Therefore, the establishment and improvement of the incentive mechanism of college logistics staff is the objective requirement of adapting to the market competition, the important measures of improving staff's quality, and the central content of the logistics management ${ }^{[3]}$. In practical applications, motivation can be divided into economic motivation and non-economic motivation according to the content.

\section{Existing Problems in the Motivation of Logistics Enterprises Staff in Universities}

Incentive strategy lacks the support of scientific theory. The motivation of some logistics managers to the staff still has problems in understanding. For example, it is thought that the most effective or even the only way to stimulate the enthusiasm of the staff is "money". However, improving staff salaries and benefits is purely a cost-effective approach. Therefore, the contradiction 
and indecisiveness will occur in motivating staff work enthusiasm and improving the treatment of the staff. Some senior managers of college logistics enterprises are subjective and arbitrary in the decision-making, and fail to perform scientific incentives from the objective reality, which results in the staff psychological inadaptation, enthusiasm frustration and even the reduction in the loyalty to enterprises and brain drain.

Incentive work lacks the support of the basic management. Incentive work is a systematic project, which is the integration of the values of enterprise managers and the management actual operation technology, and embodies in every aspect of the construction of human resource management system. For example, position analysis attributes to straightening out the functions of departments, and improving work efficiency. However, most of the current logistics enterprises in universities have not yet carried out a detailed position analysis, which leads to the phenomena that the position responsibilities among the departments are unclear, the position arrangement according to the person and time is relatively prominent, and the confusion and crossing absence appear in position responsibilities among the departments. Meanwhile, because of the lack of position analysis and position description, the responsibilities of different positions are not clear, which easily lead to the buckpassing, the reduction in the rationality of performance appraisal, and the frustration of the staff enthusiasm $^{[4]}$.

Incentive measures lack the support of sustainable ideas. Enterprise development depends on talents. However, based on the suspicion of the employee's loyalty, many college logistics enterprise managers only pay attention to the employment instead of personnel training, are willing to spend money on the employment instead of the investment in the personnel training, poach talents from the same enterprises instead of sending the staff to learn and training, which in turn makes the logistics staff in universities difficulty to maintain the loyalty to the enterprises under the condition of no understanding of the growth opportunities provided by the enterprises, and some employees stand on one's side apparently but actually on another's. The stock of college logistics enterprise human resource is not optimistic.

\section{Ways of the Motivation of Logistics Staff in Universities}

Establish a sound salary system. First, the design of the salary system should consider both internal and external factors of the enterprises. The internal factors which the enterprises should consider in the salary design include the business payment ability, the enterprise culture, the school salary policy, the staff difference and the position difference. The external factors include the country's policies and regulations, the labor market supply and demand situation, the social labor productivity, the income level of social counterparts and the residents' living cost $^{[5]}$. The factors including the school salary policy, the business actual payment ability, the country's policies and regulations, and the labor market supply and demand situation should be placed emphasis on.

Second, the salary structure should be discretely designed in the salary system. Different types of staff should be different when the enterprises design the staff salary structure. The managers and technical backbone is the core strength of the enterprises, who play a vital role in the survival and development of the enterprises. Therefore, the structural wage system should be implemented. The specific structure is: wages = basic salary + position salary + bonus + other special bonus + welfare. The basic salary should be determined based on the minimum wage standard in the area and in combination with the qualifications, length of service, etc. The position salary should be determined according to the responsibilities of different positions (duties), the technical requirements of labor intensity level towards the positions. The bonus should be determined according to the reasonable performance appraisal results. The other special bonus mainly refers to the reasonable proposal award and grievance award. The welfare includes vacation, various social insurances and provident fund. Because the labor skills requirements of other general staff are relatively low, and it is easy to find alternative workers from the social labor market, the market pricing wage system should be implemented, that is, under the premise of not less than the local minimum wage, the market-based wage system should be implemented on the above staff ${ }^{[6]}$. 
Establish a reasonable human resource system. First, the positions should be arranged in combination with the characteristics of the enterprises, and the position functions and responsibilities should be clarified, which will effectively avoid the arbitrary work assignment, overcome the blindness of personnel employment, provide an objective and impartial basis for the staff performance assessment, and be conducive to give full play to organizational efficiency. All in all, the management failure inside the college logistics enterprises ascribes to the lack of the establishment of the corresponding management system. In fact, institutionalization and flexibility are complementary. The key lies in integrating the flexible mechanism into the system. At the same time, the system must be conducive to the organizational coordination. The implementation of position assessment should resolutely abandon the measures such as "worst staff elimination system", which seriously dampen the staff enthusiasm.

Second, the development and growth of the staff should be cared about, and the participation of the staff in enterprise management should be encouraged. Under the premise of understanding the individual wishes of the staff, enterprises can help the staff to design their own professional goals, and strive to create the conditions to achieve the goals, which not only improves the staff work effort degree and the sense of belonging to the enterprises, but also are conductive to the long-term stability, development and growth of the enterprises. Enterprises should leave the staff participate in the formulation and revision of various goals and systems such enterprise development strategy objectives and annual work objectives via multi-channels and multi-orientations, and make the aspects of staff bonus distribution, performance assessment, further study, award recognition and position promotion be transparent and open, which attribute to the further promotion of the management democratization process. The staff should be really left participate in the process of business decision-making and management by the means of holding staff forum and office meeting of the staff representatives.

Third, the community organizations should be made full use of to enhance the vitality of the enterprises. All the resources of college logistics enterprises are very limited. Therefore, the management layer must attach great importance to the interpersonal relationships in the process of taking care of the work. In this way, the community organizations can be used to achieve the goal of the unification of personal goals and organizational goals.

Establish a viable staff training system. First, the managers should actively participate in staff training. Enterprise excellent human resources are the group that identifies the organizational goals and culture, and is willing to work together with the organization. These human resources should be developed within the enterprises. The training system of college logistics enterprises often reflects the management idea of the leaders, and also determines the position of the training in the enterprises. The successful training management especially needs the participation and support of the enterprise decision-making layer and management layer. Otherwise, the training work is easy to encounter the frustration. At the same time, the managers should be aware that the training is an incentive rather than just welfare. The concept that the training is like the work, and the test can be accepted at any time should be established in the staff. Therefore, the managers should always communicate with the training departments and staff to make the instructors clarify the needs of the enterprises for the staff, and integrate the needs of the enterprises into the training practice, which attributes to improving the job skills corresponding to the staff and job, and enhancing the training efficiency.

Second, the scientific training program should be clarified. The training program is a staff training program based on the near, medium and long-term development objectives of the enterprises. A scientific and effective training program can improve the staff's work attitude, increase the staff's cultural literacy, train the staff's capacity, and ultimately achieve the purpose of improving business performance ${ }^{[7]}$. In order to develop a scientific and effective training program, the enterprises must carefully analyze the training needs, and make a systematic and scientific planning and arrangement for the staff training content, methods, teachers, courses, funds and time. Different training objectives should be put forward, and different training contents should be designed according to different training objectives and staff so that the plan not only is consistent with the overall development needs of the enterprises, but also meet the current needs of the enterprises. 
Third, the scientific staff training system should be established. From the perspective of the staff individuals, the training can help them to give full play to their human resources potential, realize their own values at a greater degree, improve the job satisfaction, and enhance the sense of belonging and responsibility to the enterprises. Therefore, it is necessary to establish a scientific staff training system, investigate and analyze the training needs from three levels of organization, work and individual, rationally make training programs, focus on the evaluation and feedback of the training effect, and conduct the evaluation on the training "response, learning effect and results".

\section{Summary}

The problems in the motivation of college logistics enterprises staff from the perspective of socialization are mainly manifested in the following aspects. First, the incentive strategy lacks the support of scientific theory. Second, the incentive work lacks the support of basic management. Third, the incentive measures lack the support of sustainable ideas. In regards to the problems in the motivation of college logistics enterprises staff from the perspective of socialization, the measures including the establishment of perfect salary system, reasonable human resources system and a feasible staff training system should be taken.

\section{References}

[1] LI Mingchao. Research on the effectiveness of incentive mechanism of logistics personnel management in universities [J]. Management Observation, 2014, (20): 179-181.

[2] HUANG Zuonv. Exploration on the incentive of logistics personnel outside the personnel structure in universities [J]. Higher Education Forum, 2013, (11): 104-106.

[3] HU Huaiwen. Research on the incentive way of staff in college logistics management [J]. Qunwen World, 2011, (20): 297.

[4] XU Xunfeng. Research on the incentive mechanism of logistics human resources in universities [J]. College Logistics Research, 2011, (05): 42-44.

[5] WANG Xiuqin. Staff incentive mechanism of college logistics operational entity [J]. Human Resources Development, 2011, (08): 93-94.

[6] ZHANG Xiao, DU Deqing, SU Zhuxiang. Construction of the incentive mechanism in college logistics management [J]. Journal of Nantong Vocational College, 2010, (02): 43-46.

[7] ZHU Chunsheng. Exploitation on the incentive problems of college logistics enterprise employees [J]. Journal of Yangzhou University (Higher Education Research Edition), 2010, (01): 93-96. 